\title{
Study of cases of double mishap in a tertiary care teaching hospital
}

\author{
Fasiha Tasneem*, Vijayalakshmi Shanbhag
}

Department of Obstetrics and Gynecology, Dr. SCGMC, Nanded, Maharashtra, India

Received: 21 January 2019

Accepted: 05 March 2019

\section{*Correspondence:}

Dr. Fasiha Tasneem,

E-mail: faisha.aziz@yahoo.com

Copyright: (c) the author(s), publisher and licensee Medip Academy. This is an open-access article distributed under the terms of the Creative Commons Attribution Non-Commercial License, which permits unrestricted non-commercial use, distribution, and reproduction in any medium, provided the original work is properly cited.

\section{ABSTRACT}

Background: "Make every mother and child count"- the slogan for World health day 2005 reflects the reality and need of the society even today. In India, many women die due to pregnancy-related complications and those who survive suffer from severe maternal morbidity. Authors have been impressed that the same obstetric conditions that kill mothers are also responsible for most of the stillbirths and many of the neonatal deaths as well. This is the study to identify the risk factors that has an effect on the health of both mother and baby, to evaluate the complications leading to maternal and perinatal morbidity or mortality so that timely interventions to prevent maternal and perinatal morbidity and mortality can be made.

Methods: All the cases getting admitted in Dr SCGMC Nanded are analysed for maternal and foetal outcome over the study period of 18 months. The cases with both maternal and perinatal morbidity or mortality are included in the study. The associating factors and comorbidities if associated with the cases of double mishap are studied.

Results: During the study period of $18 \mathrm{mths}$, there were 21905 deliveries conducted in the study hospital and 742 reffered cases of outside hospital deliveries, it was found that there were 204 cases of double mishap. Out of 204 cases of double mishap, $71.56 \%$ had preeclampsia, $29.41 \%$ were anaemic, $6.86 \%$ had febrile illness, $4.41 \%$ were of placenta praevia, $33.33 \%$ had abruptio placenta.

Conclusions: Authors can conclude by stating that through better antenatal care, early detection and proper management of risk factors like pre-eclampsia, anaemia and active management of third stage of labour with careful feto maternal monitoring the absolute goal of Obstetrics of having a healthy mother and healthy baby at the end of delivery can be achieved.

Keywords: Maternal mortality, Near miss, Perinatal mortality, Preeclampsia

\section{INTRODUCTION}

"Make every mother and child count"-the slogan for World health day 2005 reflects the reality and need of the society even today. Pregnancy and childbirth are a universally celebrated event. Every minute every day, a woman dies as a result of pregnancy and childbirth somewhere in the world, be it an unwed adolescent, a teenage bride for want of blood or drugs. Every year, approximately 600,000 women die of pregnancy related causes. It is shocking to learn that 98 percent of these deaths occur in developing countries. Worldwide about half a million women die as results of complications of pregnancy and childbirth. ${ }^{1}$ In India, many women die due to pregnancy-related complications and those who survive suffer from severe maternal morbidity. ${ }^{2}$

Pregnant women's health status is not reflected by mortality indicators alone hence the concept of severe acute maternal morbidity is an apt for the present health providing system. ${ }^{3,4}$ Maternal mortality is an important indicator of efficiency of health care system. Maternal mortality has been identified as a priority on health policy and research agendas for developing countries. ${ }^{5}$ Maternal 
mortality is "Just the tip of iceberg" has vast base to the iceberg maternal morbidity which remains undescribed. "Maternal near miss" surveillance is an effective tool for improving safe motherhood programs. ${ }^{6}$

Authors have been impressed that the same obstetric conditions that kill mothers are also responsible for most of the stillbirths and many of the neonatal deaths as well. ${ }^{7}$ Mother and baby must be considered as one unit. If the fetus is known to be SGA, the risk of stillbirth is reduced by $50 \%$ compared with cases where the SGA is not recognized. ${ }^{8}$ Double mishap are the cases where both mother and baby both are affected i.e. cases with maternal morbidity or mortality with perinatal morbidity or mortality.

\section{METHODS}

All the cases getting admitted in our institute are analyzed for maternal and fetal outcome. The cases with double mishaps (i.e. both maternal and perinatal morbidity or mortality) are analyzed for determinants of maternal mortality, direct and indirect causes of maternal and neonatal mortality and morbidity. The associating factors and comorbidities if associated are studied. The various causes for maternal mortality or morbidity and fetal mortality or morbidity are compared using graphs and charts.

\section{Inclusion criteria}

- All cases with maternal mortality or morbidity with fetal demise or early neonatal mortality or morbidity who give consent for the study.

\section{Exclusion criteria}

- All the cases with healthy mother and baby at the end of delivery

- All the cases with maternal mortality or morbidity but with healthy baby at the end of delivery

- All the cases with healthy mother (i.e. no maternal mortality or morbidity) but fetal demise or neonatal mortality or morbidity

- All the cases of maternal and perinatal morbidity or mortality not consenting for the study.

\section{RESULTS}

In present study conducted on the cases of double mishap, i.e., maternal and perinatal morbidity and mortality, it was found that during the study period of 18 months, there were 21905 deliveries conducted in the study hospital and 742 referred cases of outside hospital deliveries, it was found that there were 204 cases of double mishap. Cases with maternal morbidity and perinatal mortality were more i.e. $74.02 \%$ and only $0.49 \%$ of the cases were of maternal mortality with perinatal morbidity (Figure 1).

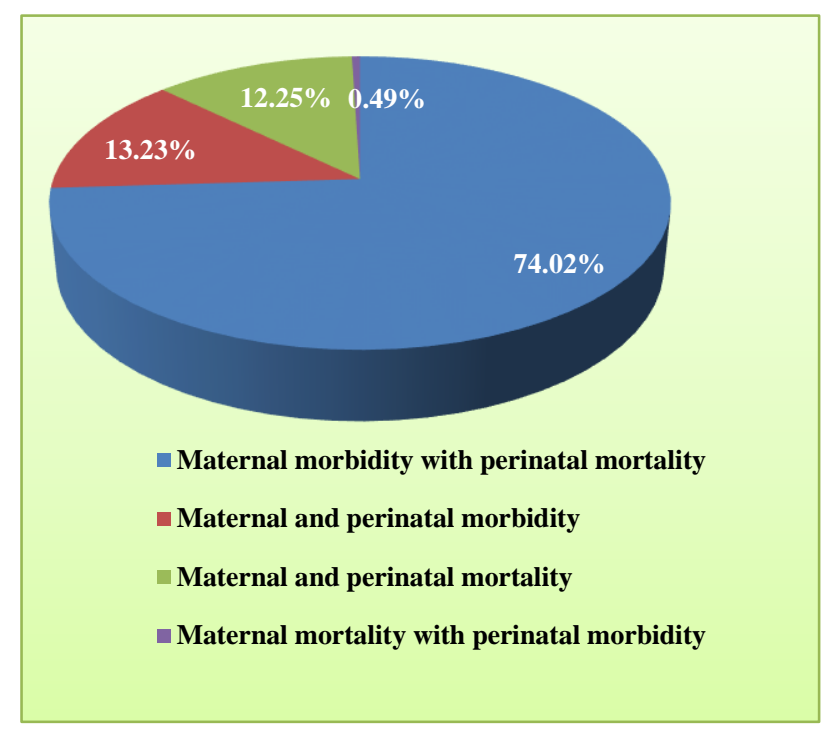

Figure 1: Distribution of cases of double mishap.

Maternal mortality was seen in $12.74 \%$ of cases and maternal morbidity was seen in $87.25 \%$ of cases. Among the perinatal outcome, perinatal mortality accounted for $86.27 \%$ and perinatal morbidity accounted for $13.72 \%$ of the cases. Majority of the cases i.e. $72.05 \%$ were referred from primary health centers and $18.63 \%$ of the cases were unbooked (Table 1).

Table 1: ANC status of the cases of double mishap.

\begin{tabular}{|l|c|l|}
\hline ANC status & $\begin{array}{l}\text { No. of cases of double } \\
\text { mishap }\end{array}$ & $\%$ \\
\hline Referred cases & 147 & 72.05 \\
\hline Unbooked & 38 & 18.63 \\
\hline Booked & 19 & 9.31 \\
\hline Total & 204 & 100 \\
\hline
\end{tabular}

There was no association of parity in cases of double mishap, though the cases of double mishap with abruption and anemia were found to be more common in multigravida (Table 2).

Table 2: Parity of the cases of double mishap.

\begin{tabular}{|l|l|l|}
\hline Parity & No. of cases & $\%$ \\
\hline Primi & 102 & 50 \\
\hline Multi & 102 & 50 \\
\hline Total & 204 & 100 \\
\hline
\end{tabular}

Majority of patients $46.08 \%$ were in the age group of 21 25years. The mean age was 23.42 years. Maximum age was 37 years and minimum age was 18 years. Standard deviation is 4.24 . The standard error value is 0.29 (Table $3)$. 
Table 3: Age distribution of the cases of double mishap.

\begin{tabular}{|l|l|l|l|l|l|}
\hline Age distribution & No. of cases of double mishap & Percentage & Maximum age & Minimum age & Mean \\
\hline S20year & 68 & 33.33 & 18 year & \\
\hline 21-25year & 94 & 46.08 & & 23.42 year \\
\hline 26-30year & 25 & 12.25 & & \\
\hline >30year & 17 & 8.33 & 37 year & \\
\hline Total & 204 & 100 & & \\
\hline
\end{tabular}

Among the cases of double mishap 201 cases were delivered and 3 cases were undelivered (mortality of undelivered mother) and it was found that preterm deliveries $(74.62 \%)$ were more common leading to perinatal morbidity and mortality, especially in cases associated with abruption, placenta previa and preeclampsia (Table 4).

Table 4: Gestational age among the delivered cases of double mishap.

\begin{tabular}{|l|l|l|}
\hline Gestational age & No. of deliveries & $\%$ \\
\hline Term & 51 & 25.37 \\
\hline Preterm & 150 & 74.62 \\
\hline Total cases delivere & 201 & 100 \\
\hline
\end{tabular}

Vaginal mode of delivery was seen in $78.11 \%$ of the cases and amongst the vaginal deliveries $80.89 \%$ were induced vaginal deliveries.

Table 5: Risk factors in the cases of double mishap.

\begin{tabular}{|l|l|l|}
\hline Risk factors & No of cases & $(\%)$ \\
\hline PIH & 146 & 71.55 \\
\hline Abruptio placenta & 68 & 33.33 \\
\hline Anemia & 60 & 29.41 \\
\hline HELLP & 28 & 13.72 \\
\hline Febrile illness & 14 & 6.86 \\
\hline Multiple gestation & 11 & 5.39 \\
\hline Placenta previa & 9 & 4.41 \\
\hline Hepatitis & 9 & 4.41 \\
\hline
\end{tabular}

A $17.41 \%$ had undergone cesarean section and $2.49 \%$ required laparotomy with repair for ruptured uterus. Preeclampsia (71.55\%), placental abruption (33.33\%) and anemia $(29.41 \%)$ are the major conditions affecting both maternal and perinatal outcome.

Pre-eclampsia may lead to eclampsia, HELLP, DIC in mother resulting in maternal morbidity or mortality and also causes IUGR, SGA babies, fetoplacental insufficiency and preterm birth resulting in perinatal morbidity or mortality.

Anemia is a serious problem especially in antenatal mothers causing deterioration of both maternal and perinatal health. (Table 5, Figure 2 and 3 ).

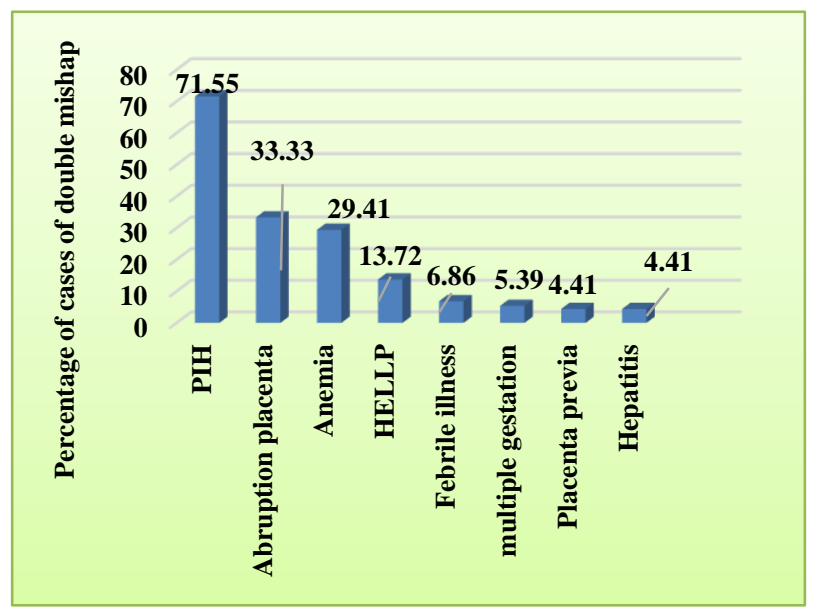

Figure 2: Risk factors in cases of double mishap.

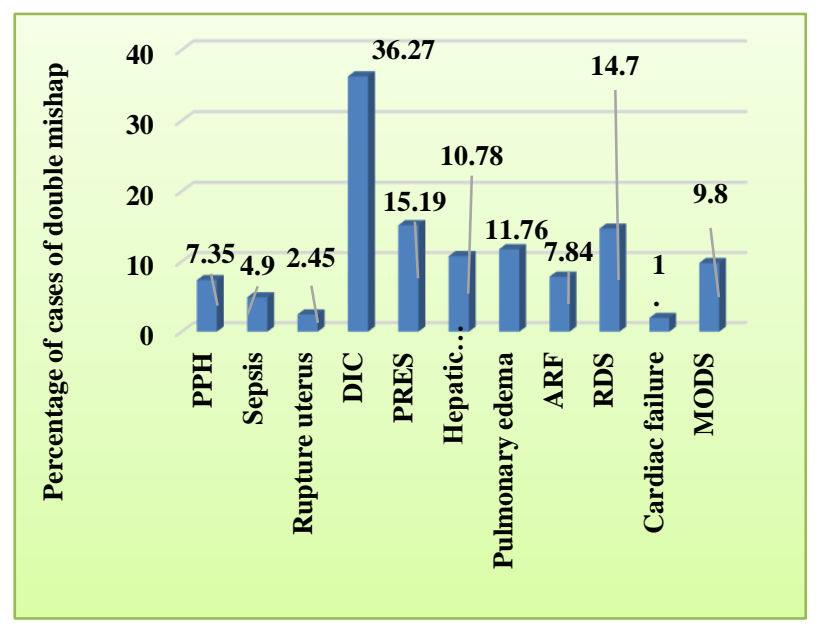

Figure 3: Complications in cases of double mishap.

Table 6: Broad interventions done in cases of double mishap.

\begin{tabular}{|l|l|l|}
\hline Broad intervention & No. of cases & $\%$ \\
\hline Cardiovascular support & 60 & 29.41 \\
\hline Ventilatory support & 38 & 18.62 \\
\hline Dialysis & 9 & 4.41 \\
\hline ICU care & 104 & 50.98 \\
\hline Surgical intervention & 38 & 18.63 \\
\hline $\begin{array}{l}\text { Transfusion of blood and } \\
\text { blood products }\end{array}$ & 155 & 75.98 \\
\hline
\end{tabular}


Broad interventions done were transfusion of blood and blood products $(75.98 \%)$, intensive care $(50.98 \%)$, cardiovascular support $(29.41 \%)$, surgical intervention $(18.63 \%)$ in the form of internal iliac artery ligation, B lynch etc, ventilatory support $(18.62 \%)$ and dialysis (4.41\%) (Table 6).

\section{DISCUSSION}

Despite the improvements in obstetric care over the few decades, maternal morbidity and mortality remains to be a challenge in the developing countries. Additionally, adverse pregnancy outcomes leading to perinatal mortality have attracted much public health attention globally. The high MMR is similarly accompanied by high rates of perinatal mortality. There are no studies done till date about the cases where both maternal and perinatal factors are taken into consideration so, the studies done on maternal and perinatal mortality and morbidity are considered in the discussion.

Most of the maternal deaths were in unbooked cases and was consistent with the study by Ashok $\mathrm{V}$ et al. ${ }^{9}$ In the study by Mustafa $\mathrm{R}$ et al, the booking status showed that $90.4 \%$ of near miss cases were unbooked and all deaths occurred in the unbooked cases. ${ }^{10}$ In the study done by Roopa P Rathod AD S et al, a huge burden of maternal near miss cases $96.2 \%$ and $86.96 \%$ of maternal deaths were referred, primiparas were slightly more in the near miss group. ${ }^{11}$ In the study by Bansal $\mathrm{M}$ et al, multipara cases were slightly more in near miss cases while primipara was slightly more in maternal death cases, $41.02 \%$ of near miss cases were found in 18-24 year of age group while $47.36 \%$ cases of maternal death were found in 25-30 year of age group. ${ }^{12}$ In the study by Panda $\mathrm{S}$ et al, and Purandare $\mathrm{N}$ et al, majority of maternal deaths have occurred in the age group of 21-25 years. ${ }^{13,14}$ According to Panda S et al, 188 and Ashok V et al, anemia is the leading indirect cause of maternal mortality. ${ }^{9,13}$ According to a study by Mlambo $\mathrm{C}$ et al, hemorrhage is the highest cause of maternal deaths. ${ }^{15}$ In the study Rathod AD et al, on maternal near miss cases hemorrhage $(26.70 \%, \mathrm{n}=43)$ is the leading cause, followed by anemia $(24.84 \%, \mathrm{n}=40)$, hepatitis $(16.77 \%$, $\mathrm{n}=27)$ and hypertensive disorders of pregnancy $(11.80 \%$, $\mathrm{n}=19) .{ }^{16}$ The study by Rose M Pembeni NM et al, found that the common causes of perinatal deaths included preeclampsia and eclampsia, prolonged and obstructed labor and prematurity. ${ }^{17}$ In the study by Fallahian $M$ et al, neonatal mortality increased by 5.7 times in the group of pregnant mothers inflicted with hypertensive disorders. ${ }^{18}$ In the study by Vogel JP et al, on maternal complication and perinatal mortality, Hypertensive disorders were the most common (2.7\%), followed by other complications/diseases (2.5\%), hemorrhagic disorders $(1.1 \%)$, and infective disorders $(0.6 \%) .{ }^{19}$ In a study by Allinson ER et al, the maternal conditions in late still birth and early neonatal death, it is found that obstetric hemorrhage in the form of abruption, placenta previa, ruptured uterus accounted for $64(15.4 \%)$ cases of late still birth and $20(7.4 \%)$ cases of early neonatal death followed by hypertension which accounted for 96 $(23.1 \%)$ of the cases of late still birth and $23(8.5 \%)$ cases of early neonatal death. ${ }^{20}$ In the study by Iwuh IA et al, on maternal near miss cases 39 women $(34.8 \%)$ who had massive blood transfusion ( $>5$ units of red cells), 34 $(30.4 \%)$ who had a hysterectomy, 45 (40.2\%) who required intubation and ventilation, and 23 (20.5\%) who were admitted to the tertiary hospital main intensive care unit. $^{21}$

\section{CONCLUSION}

'Let's stop child and maternal deaths. Even though there are many national programs initiated by the government for improving mother and child health, there are considerable number of cases where both maternal and fetal health is compromised indicating that there is still a need for improvement at the grass route level to promote maternal and perinatal wellbeing. But in present study, it is evident that cases of maternal mortality is less indicating the effective management of the cases at tertiary level so that the mortality could be prevented but there was maternal morbidity in the form of cardiorespiratory support, ICU care, transfusion of blood and blood products and surgical intervention.

Authors can conclude by stating that through better antenatal care, early detection and proper management of risk factors like pre-eclampsia, anemia and active management of third stage of labor with careful feto maternal monitoring, multidisciplinary approach for near miss cases and better NICU facilities the absolute goal of Obstetrics of reducing maternal morbidity and mortality, and having a healthy mother and healthy baby at the end of delivery can be achieved.

Funding: No funding sources Conflict of interest: None declared

Ethical approval: The study was approved by the Institutional Ethics Committee

\section{REFERENCES}

1. World health organization (2005) attending to 136 million births, every year. Make every mother and child count. The world report 2005. World health organization, Geneva.2005: 62-63. Available at: https://www.scirp.org/(S(vtj3fa45qm1 ean45vvffcz55 ) )/reference/ReferencesPapers.aspx?ReferenceID $=15$ 69984.

2. Khosla AH, Mehra R, Dua D, Gupta P. Maternal morbidity and mortality: an assessment of prevalence and aetiological factors. Obs Gynae Today. 2006;11:447-9.

3. Stones W, Lim W, Al-Azzawi F, Kelly M. An investigation of maternal morbidity with identification of life-threatening'near miss' episodes. Health Trends. 1991;23(1):13-5. 
4. Sivalingam N, Looi KW. Clinical experience with management of near-miss cases in obstetrics. Med J Malaysia. 1999;54(4):496-503.

5. Ramos S, Karolinski A, Romero M, Mercer R. A comprehensive assessment of maternal deaths in Argentina: translating multicentre collaborative research into action. Bullet World Health Org.2007;85(8):615-22.

6. Maternal near miss review, operational guidelines, December, 2014. Maternal Health Division. Ministry of health and family welfare, GOI.

7. Goldenberg RL, McClure EM, Bhutta ZA. Beliz an JM, Reddy UM, Rubens CE, et al. Stillbirths: the vision for 2020. Lancet. 2011;377:1798-805.

8. Gardosi J, Madurasinghe V, Williams M, Malik A, Francis A. Maternal and fetal risk factors for stillbirth: population-based study. BMJ. 2013;346:f108.

9. Ashok V, Santosh M, Anupa S. A study on maternal mortality. J Obstet Gynecol India. 2008;58(3):226229.

10. Mustafa R, Hashmi H. Near-miss obstetrical events and maternal deaths. J Coll Physic Surg Pak. 2009;19(12):781-5.

11. Roopa PS, Verma S, Rai L, Kumar P, Pai MV, Shetty J. "Near miss" obstetric events and maternal deaths in a tertiary care hospital: an audit. J Preg. 2013;2013.

12. Bansal M, Lagoo J, Pujari K. Study of near miss cases in obstetrics and maternal mortality in Bastar, Chhattisgarh, India. Int J Reprod Contracept Obstet Gynecol. 2016;5(3):620-3.

13. Panda S, Das BB, Patnaik A. An investigation into maternal mortality. Paper presented at the $44^{\text {th }}$ all India congress of obstetricians and gynaecologists, Ahmedabad; 2000:28-31.

14. Purandare N, Chandock AS, Upadhya S, Sanjanwala SM, Saraogi RM. Maternal mortality at a referral centre: a five year study. J Obstet Gynecol India 2007;57:248-50.

15. Mlambo C, Chinamo C, Zingwe T. An investigation of the causes of maternal mortality in Zimbabwe. Med J Social Sci. 2013;4(14):615.

16. Rathod AD, Chavan RP, Bhagat V, Pajai S, Padmawar A, Thool P. Analysis of near-miss and maternal mortality at tertiary referral centre of rural India. J Obstet Gynecol India.2016;66(1):S295-300.

17. Rose M pembeni NM, Jonathan R, Mughamba J. Perinatal mortality and associated factors among deliveries in three municipal hospitals of Dar Es Salaam. Tanzania. J Pediatr Neonatal Care. 2014;1(4):00022.

18. Fallahian M, Emadolsadaty N. Effects of maternal hypertension on the taleghani hospital's neonates in 1378. J Reprod Infertil. 2001;1380(2):48-53.

19. Vogel JP, Souza JP, Mori R, Morisaki N, Lumbiganon $\mathrm{P}$, Laopaiboon $\mathrm{M}$, et al. Maternal complications and perinatal mortality: findings of the world health organization multicountry survey on maternal and newborn health. BJOG: An Int J Obstetr Gynaecol. 2014;121:76-88.

20. Allanson ER, Muller M, Pattinson RC. Causes of perinatal mortality and associated maternal complications in a South African province: challenges in predicting poor outcomes. BMC pregnancy and childbirth.2015;15(1):37.

21. Iwuh IA, Fawcus S, Schoeman L. Maternal nearmiss audit in the Metro West maternity service, Cape Town, South Africa: A retrospective observational study. South African Med J. 2018;108(3):171-5.

Cite this article as: Tasneem F, Shanbhag V. Study of cases of double mishap in a tertiary care teaching hospital. Int J Reprod Contracept Obstet Gynecol 2019;8:1650-4. 